Case Report

\title{
Sertoli-Leydig Cell Tumour and DICER1 Mutation: A Case Report and Review of the Literature
}

\author{
B. Wormald $\mathbb{D}^{1}{ }^{1}$ S. Elorbany, ${ }^{1}$ H. Hanson, ${ }^{1}$ J. W. Williams, ${ }^{1}$ S. Heenan, ${ }^{1}$ and D. P. J. Barton ${ }^{2}$ \\ ${ }^{1}$ St George's Hospital, UK \\ ${ }^{2}$ St George's Hospital and the Royal Marsden Hospital, UK
}

Correspondence should be addressed to B. Wormald; ben.wormald@nhs.net

Received 20 June 2018; Accepted 6 September 2018; Published 25 September 2018

Academic Editor: Giampiero Capobianco

Copyright (C) 2018 B. Wormald et al. This is an open access article distributed under the Creative Commons Attribution License, which permits unrestricted use, distribution, and reproduction in any medium, provided the original work is properly cited.

\begin{abstract}
Sertoli-Leydig cell tumours of the ovary (SLCT) are rare tumours predominantly caused by mutations in the DICER1 gene. We present a patient with a unilateral SLCT who had an underlying germline DICER1 gene mutation. We discuss the underlying pathology, risks, and screening opportunities available to those with a mutation in this gene as SLCT is only one of a multitude of other tumours encompassing DICER1 syndrome. The condition is inherited in an autosomal dominant fashion. As such, genetic counselling is a key component of the management of women with SLCT.
\end{abstract}

\section{Introduction}

Sertoli-Leydig cell tumours of the ovary (SLCTs) are a rare type of sex cord-stromal tumour, constituting less than $0.5 \%$ of all ovarian cancers. SLCTs contain Sertoli and Leydig cells which are somatic cells found within the male gonad. It is likely that SLCTs derive from primitive pregranulosa cells and therefore represent a pseudo-male gonadal genesis in the ovary. Patients typically present in the 2nd or 3rd decade of life and often have features of androgen excess, such as amenorrhoea, hirsutism, deepening of the voice, and clitoral enlargement. The vast majority, more than $95 \%$ of tumours, are unilateral, FIGO Stage 1, and either moderately or poorly differentiated. It is increasingly clear that the pathogenesis of SLCT is through mutation in the DICER1 gene [1].

\section{Case Presentation}

A 15-year-old girl presented with a background of erratic menstrual periods following menarche at age of 12 years. By first contact she had experienced amenorrhoea for 6 months followed by continuous daily vaginal bleeding for 3 months. She had noticed hair loss, receding hairline, and coarse dark hair on her abdomen, thighs, and bottom. Clinical examination revealed a normally developed female without virilisation of the external genitalia or a change in voice. She was pain free.

Hormone profile revealed raised testosterone $(10.1 \mathrm{nmol} / \mathrm{l}$ Ref: 0.5-3.0 nmol/l), suppressed FSH $(<0.1 \mathrm{IU} / \mathrm{L}$ Ref: 1-11 $\mathrm{iu} / \mathrm{L})$, and borderline SHBG (21 nmol/1 Ref: $18-114 \mathrm{nmol} / \mathrm{L})$. AFP was raised ( $137 \mathrm{kU} / \mathrm{L}$ Ref: $0-5.8 \mathrm{kU} / \mathrm{L})$ but all other tumour markers, including Beta-HCG and Inhibin, were normal. Urine steroid profile was normal.

Ultrasound examination of the abdomen and pelvis, Figure 1 , revealed a complex $7 \mathrm{~cm}$ left ovarian lesion with internal vascularity but otherwise normal pelvic organs and adrenal glands. MRI, Figure 2, confirmed an abnormal but welldefined $7 \mathrm{~cm}$ left adnexal lesion of predominant intermediate T2 signal interspersed with high signal cystic areas separated by low signal septa. The clinical picture was of a primary ovarian tumour with ectopic production of androgens, and not the more common germ cell tumour.

The case was discussed at the paediatric and gynaecologic oncology MDT. A laparoscopic left oophorectomy with preservation of the ipsilateral fallopian tube was performed with a secondary Pfannenstiel incision used to extract intact the specimen. The tumour which was more solid than cystic was $11 \mathrm{~cm}$ in size with no discernible normal ovarian tissue visible. A small nodule on the right ovary was excised. There were no other sites of disease. All other organs and 


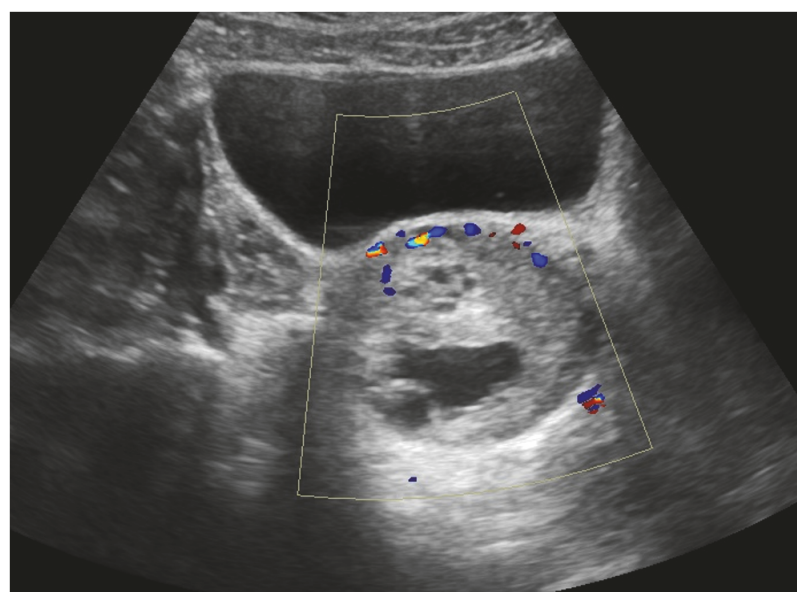

FIgURE 1: Ultrasound image of ovarian lesion.

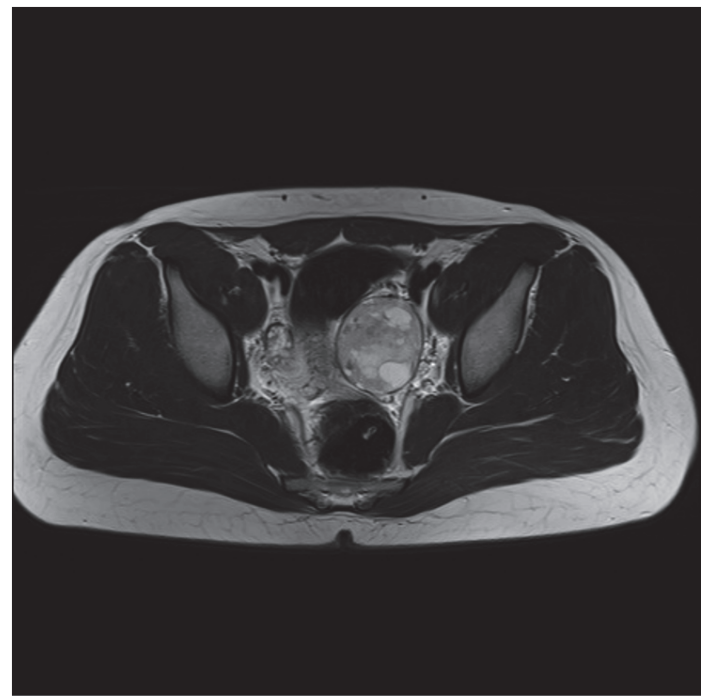

FIGURE 2: MRI image of ovarian lesion.

peritoneal surfaces were normal. The postoperative course was uneventful.

Histological analysis, Figures 3 and 4, indicated a predominantly poorly differentiated Sertoli-Leydig cell tumour, retiform pattern, with heterologous mucinous elements. The right ovarian nodule was benign.

Following multidisciplinary team discussion and parental consent, adjuvant chemotherapy was commenced, in a monthly regime of Bleomycin 28500 IU on Day 1, Etoposide $190 \mathrm{mg}$ daily on Days 1-5, and Cisplatin $38 \mathrm{mg}$ daily on Days 1-5 for 3 cycles. Starting prior to chemotherapy commencement, a GNRH analogue, Leuprorelin 3.75mg per month, was administered for 4 months for ovarian protection. The patient became neutropenic following cycle 1 and received Filgrastim $300 \mathrm{mcg}$ for 6 days on Days 6-10 of Cycle 2 . There were no further episodes of neutropenia. Following cessation of Leuprorelin, menstruation resumed on a regular monthly cycle. She completed her treatment 2 years ago and been reviewed every 3 months. She has had normal

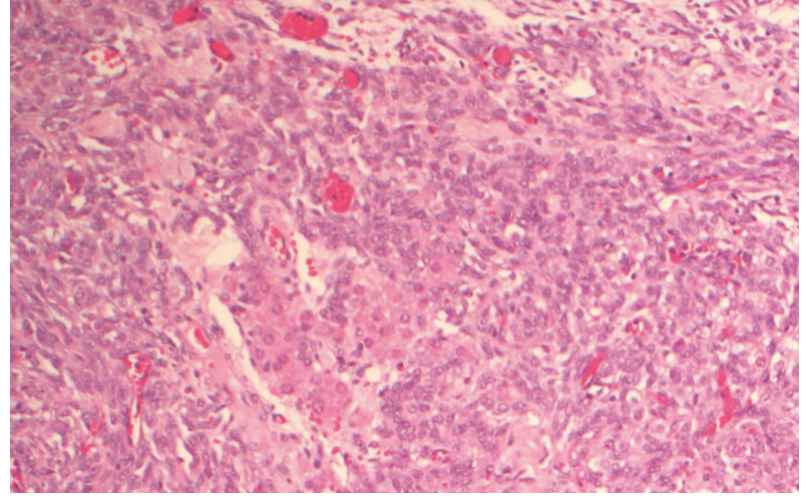

Figure 3: Microscopic view of specimen.

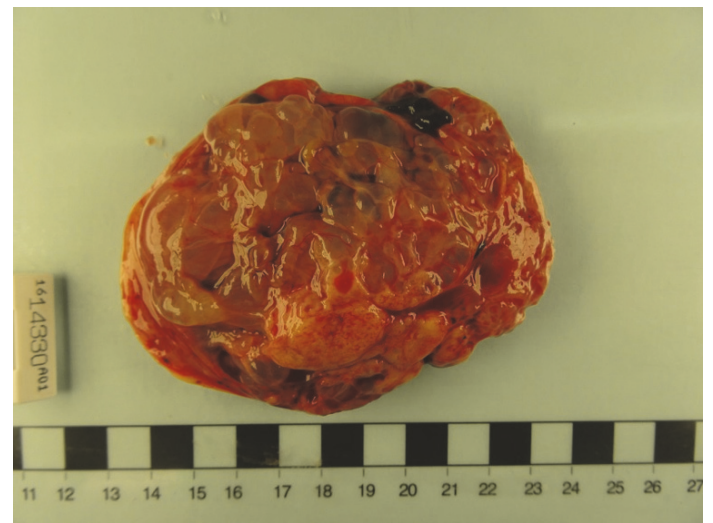

FIGURE 4: Macroscopic specimen.

tumour markers, including testosterone and AFP, and normal abdominopelvic ultrasound scans throughout this period. Following genetic analysis a germline DICER1 mutation was discovered, inherited from her father and shared by her 19year-old sister.

\section{Discussion}

DICER1 is located on chromosome 14q32.13 and contains 27 exons. Dicerl is an RNase III endoribonuclease which has several functions but crucially is involved in the microRNA (miRNA) biogenesis pathway. Dicerl processes precursor miRNA into functional mature miRNA through the cleaving of dsRNA into two RNA strands. RNA IIIa and RNA IIIb domains are responsible for $3 p$ and $5 p$ miRNAs, respectively. The miRNAs act as tumour suppressors in silencing mRNA expression [2].

DICER1 syndrome is a familial tumour susceptibility syndrome associated with pleuropulmonary blastoma; ovarian sex cord-stromal tumours; cystic nephroma; thyroid gland neoplasia; and other rare benign and malignant tumours. Features of DICER1 syndrome may present in childhood, but up to $95 \%$ of DICER1 carriers do not develop any significant clinical features by age $10[3,4]$. 
DICER1 related conditions are inherited in an autosomal dominant fashion. Penetrance is currently unknown but thought to be low except patients who have thyroid neoplasia. This is supported by the most recent estimated prevalence of germline DICER1 mutation from population databases which is $1: 10600$ [4].

Germline mutations are typically truncating loss of function mutations. These are mainly single-nucleotide substitutions that produce new stop codons and small insertions or deletions within exons that shift reading frame. The mutations truncate the open reading frame before the end of the RNase IIIb domain, and as such result in complete loss of Dicer protein function [5].

Typically, pathology results from a somatic mutational insult to the remaining wild type allele. This mutation predominantly occurs within exons 24 or 25 in the RNase IIIb domain at one of five hotspot sites (E1705, D1709, E1788, D1810, or E1813) located in the metal-binding site. This affects balance between $5 p$ and $3 p$ miRNA [6].

Previously, up to $60 \%$ of SLCT were thought to contain somatic DICER1 mutations; however, more recently, when centrally reviewed pathology was used to discriminate SLCT pathology, nearly all SLCT contained DICER1 somatic mutations, especially in those determined to be moderately or poorly differentiated. This is against a background of at least $60 \%$ of patients having a germline mutation. Given this, all patients diagnosed with an SLCT should be tested for germline DICER1 mutation and referred for genetic counselling [7-9].

The effect of this mutation in ovarian tissue includes deregulation of genes that control gonadal differentiation and cell proliferation, downregulation of key ovarian development genes, upregulation of Sertoli cell differentiation genes, and suppression of CYP19A1 leading to reduced aromatase activity causing androgenic effect [10].

3.1. Screening. Once DICER1 syndrome is identified and the initial neoplasm has been treated, surveillance for recurrence and development of additional DICER related tumours should be considered. Genetic counselling regarding the implications of a diagnosis of DICER1 familial mutation is recommended.

In the case we present the most common residual risk including multinodular goitre and a recurrence or metachronous SLCT. There is also a small increased lifetime risk of other DICER1 related tumours such as pineoblastoma or cervical embryonal rhabdomyosarcoma. A surveillance program incorporated into the usual ovarian cancer 5-year follow-up protocol would include pelvic ultrasound every 6 months until age of 18, changing to transvaginal approach for better sensitivity in ovarian imaging, and the serum tumour markers AFP and testosterone. Pelvic imaging would be recommended until age 40 to rule out metachronous SLCT, which can be found in $6 \%$ of cases up to 14 years following initial development [7]. Symptom awareness for thyroid gland problems is advised, with low threshold for TFTS and thyroid ultrasound. Typically thyroid problems present with palpable neck lumps. The cumulative risk of multinodular goitre or thyroidectomy in women affected by DICER 1 syndrome by age 40 is $75 \%$ [11].

Educating those affected to be vigilant of symptoms such as postcoital bleeding, menstrual abnormalities, thyrotoxicity, headache, and visual disturbance and seeking medical review should they occur is also key.

Descendants of those affected have a $50 \%$ chance of inheriting the germline mutation and could be offered screening from a much earlier age. This is to incorporate pleuropulmonary blastoma, cystic nephroma, and pineoblastoma and other rarer phenotypes of DICER1 syndrome.

Screening recommendations in each country are different due to the current evidence base being inconclusive. An international consensus on surveillance guideline is not yet available. However, the following surveillance options have been suggested by teams in Canada and the USA to consider. In the UK, screening is not currently offered but guidelines will be reviewed once international consensus recommendations are published.

Current preliminary recommendations include baseline CT examination of the chest between 3 and 6 months from birth, and if normal, it is repeated when they are 2.5 to 3 years old, sandwiched by chest radiographs every 6 months to age 8 and then annually to age 12 .

Abdominal/pelvic ultrasound from birth are repeated every 6 months until age 40 . Thyroid palpation annually from age 8 with ultrasound is repeated every 3 years. Brain MRI annually from birth to age 25 is controversial $[12,13]$.

The risk of repeated ionising radiation exposure is balanced against the early detection of malignant conditions and thus likely improvement in morbidity and mortality. Units have utilised whole-body MRI to ameliorate this; however in very young patients ( $<6$ years old) the long sequencing time often requires sedation or anaesthesia, which, albeit very low, has its own risk of complications $[14,15]$.

3.2. Conclusion. A diagnosis of Sertoli-Leydig cell tumour should prompt a referral to Clinical Genetics service due to the possibility of germline mutation and familial risk of malignancy. Knowledge of a DICER1 mutation can inform the individual regarding management of the current tumour and also potential future cancer risks.

\section{Data Availability}

The relevant data to support this case report has been provided in the article. Additional data is not available to protect patient anonymity.

\section{Consent}

Written informed consent was obtained from the patient and parents for publication of this case report and accompanying images. A copy of the written consent is available for review by the Editor-in-Chief of this journal on request.

\section{Disclosure}

The present address of $\mathrm{B}$. Wormald is The Institute of Cancer Research. 


\section{Conflicts of Interest}

The authors declare that there are no conflicts of interest regarding the publication of this paper.

\section{Authors' Contributions}

All authors wrote sections of the manuscript. All authors contributed to manuscript revision and read and approved the submitted version.

\section{References}

[1] T. Gui, D. Cao, K. Shen et al., "A clinicopathological analysis of 40 cases of ovarian Sertoli-Leydig cell tumors," Gynecologic Oncology, vol. 127, no. 2, pp. 384-389, 2012.

[2] W. D. Foulkes, J. R. Priest, and T. F. Duchaine, "DICER1: mutations, microRNAs and mechanisms," Nature Reviews Cancer, vol. 14, no. 10, pp. 662-672, 2014.

[3] L. Doros, K. A. Schultz, D. R. Stewart, A. J. Bauer, G. Williams, C. T. Rossi et al., "DICER1-related disorders," in GeneReviews(R). Seattle (WA): University of Washington, Seattle University of Washington, M. P. Adam, H. H. Ardinger, R. A. Pagon, S. E. Wallace, L. J. H. Bean, and H. C. Mefford, Eds., Seattle University of Washington, Seattle, DC, USA, 2014.

[4] J. Kim, A. Field, K. A. P. Schultz, D. A. Hill, and D. R. Stewart, "The prevalence of DICER1 pathogenic variation in population databases," International Journal of Cancer, vol. 141, no. 10, pp. 2030-2036, 2017.

[5] M. Brenneman, A. Field, J. Yang et al., "Temporal order of RNase IIIb and loss-of-function mutations during development determines phenotype in pleuropulmonary blastoma / DICER1 syndrome: a unique variant of the two-hit tumor suppression model," F1000Research, vol. 4, p. 214, 2015.

[6] M. S. Anglesio, Y. Wang, W. Yang et al., "Cancer-associated somatic DICER1 hotspot mutations cause defective miRNA processing and reverse-strand expression bias to predominantly mature $3 \mathrm{p}$ strands through loss of $5 \mathrm{p}$ strand cleavage," The Journal of Pathology, vol. 229, no. 3, pp. 400-409, 2013.

[7] K. A. P. Schultz, A. K. Harris, M. Finch et al., "DICER1-related Sertoli-Leydig cell tumor and gynandroblastoma: clinical and genetic findings from the international ovarian and testicular stromal tumor registry," Gynecologic Oncology, vol. 147, no. 3, pp. 521-527, 2017.

[8] L. De Kock, T. Terzic, W. G. McCluggage et al., "DICER1 mutations are consistently present in moderately and poorly differentiated sertoli-leydig cell tumors," The American Journal of Surgical Pathology, vol. 41, no. 9, pp. 1178-1187, 2017.

[9] L. Witkowski, J. Mattina, S. Schönberger et al., "DICER1 hotspot mutations in non-epithelial gonadal tumours," British Journal of Cancer, vol. 109, no. 10, pp. 2744-2750, 2013.

[10] Y. Wang, J. Chen, W. Yang et al., "The oncogenic roles of DICER1 RNase IIIb domain mutations in ovarian sertoli-leydig cell tumors," Neoplasia, vol. 17, no. 8, pp. 650-660, 2015.

[11] N. E. Khan, A. J. Bauer, K. A. P. Schultz, L. Doros, R. M. Decastro, and A. Ling, "Quantification of thyroid cancer and multinodular goiter risk in the DICER1 syndrome: a familybased cohort study," The Journal of Clinical Endocrinology \& Metabolism, vol. 102, no. 5, pp. 1614-1622, 2017.
[12] K. A. P. Schultz, S. P. Rednam, J. Kamihara et al., "PTEN, DICER1, FH, and their associated tumor susceptibility syndromes: Clinical features, genetics, and surveillance recommendations in childhood," Clinical Cancer Research, vol. 23, no. 12, pp. e76-e82, 2017.

[13] K. van Engelen, A. Villani, J. D. Wasserman et al., "DICER1 syndrome: Approach to testing and management at a large pediatric tertiary care center," Pediatric Blood \& Cancer, vol. 65, no. 1, 2018.

[14] D. G. Sabapathy, R. Paul Guillerman, R. C. Orth et al., "Radiographic screening of infants and young children with genetic predisposition for rare malignancies: DICER1 mutations and pleuropulmonary blastoma," American Journal of Roentgenology, vol. 204, no. 4, pp. W475-W482, 2015.

[15] M. T. Bueno, C. Martínez-Ríos, A. D. la Puente Gregorio et al., "Pediatric imaging in DICER1 syndrome," Pediatric Radiology, vol. 47, no. 10, pp. 1292-1301, 2017. 


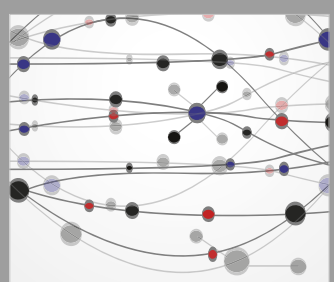

The Scientific World Journal
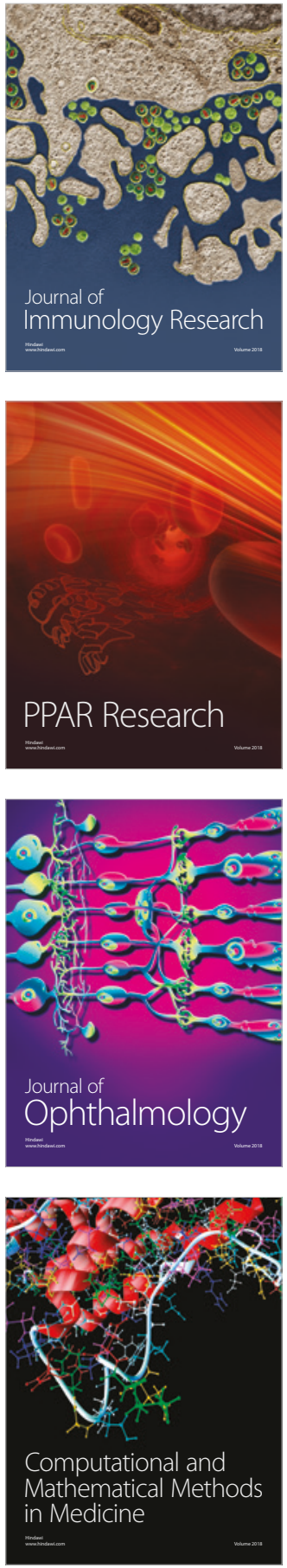

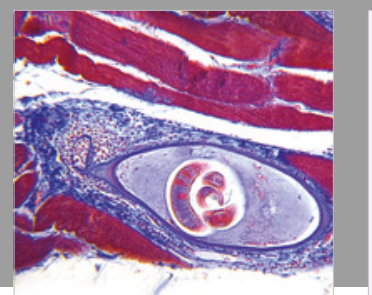

Gastroenterology Research and Practice

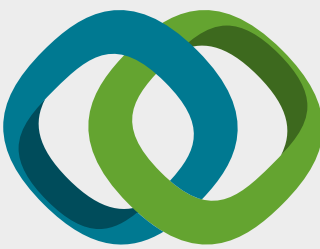

\section{Hindawi}

Submit your manuscripts at

www.hindawi.com
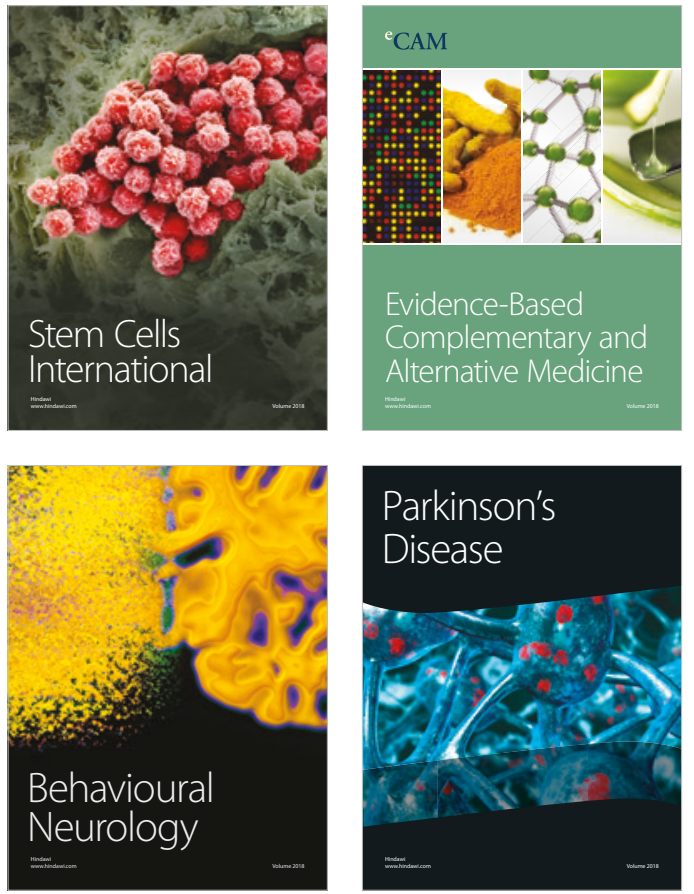

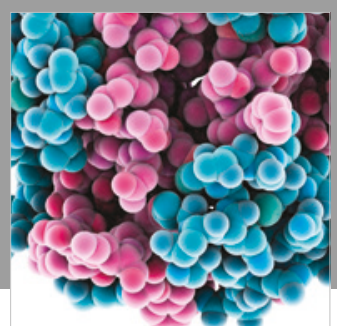

ournal of

Diabetes Research

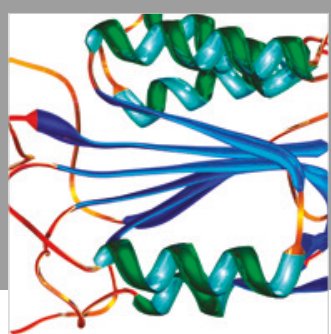

Disease Markers
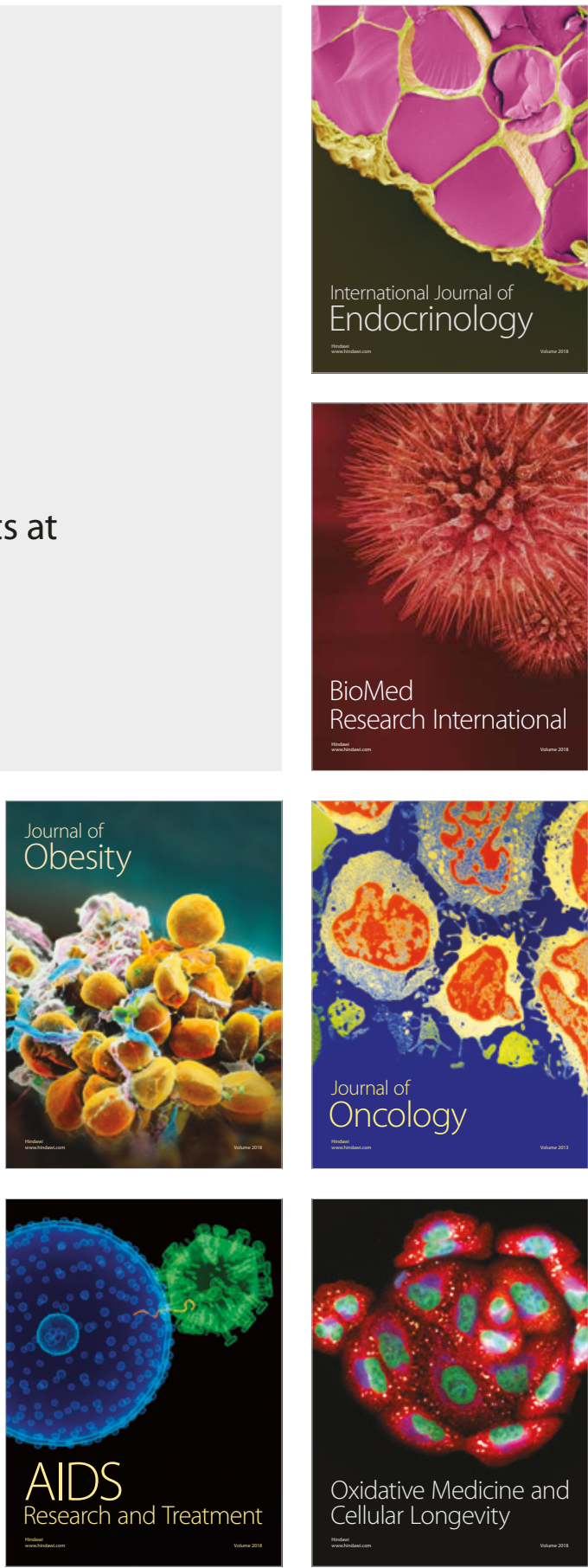